\title{
HIGH PRESSURE CALIBRATION WITH A NEW ABSOLUTE PRESSURE GAUGE
}

\section{by}

Arthur L. Ruoff, R. C. Lincoin and Y. C. Chen

January 1973

Cornel1 University

Ithaca, New York 14850

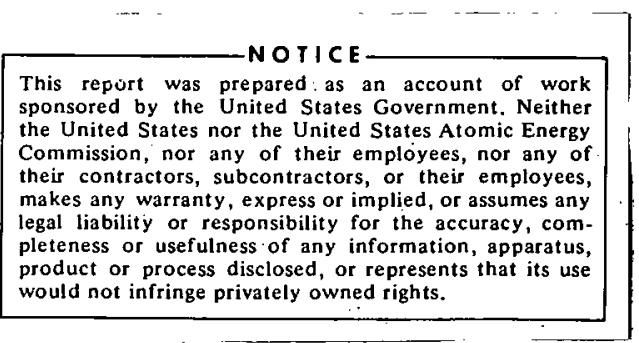

Report. \#1962

Issued by

The Materials Science Center 


\section{DISCLAIMER}

This report was prepared as an account of work sponsored by an agency of the United States Government. Neither the United States Government nor any agency Thereof, nor any of their employees, makes any warranty, express or implied, or assumes any legal liability or responsibility for the accuracy, completeness, or usefulness of any information, apparatus, product, or process disclosed, or represents that its use would not infringe privately owned rights. Reference herein to any specific commercial product, process, or service by trade name, trademark, manufacturer, or otherwise does not necessarily constitute or imply its endorsement, recommendation, or favoring by the United States Government or any agency thereof. The views and opinions of authors expressed herein do not necessarily state or reflect those of the United States Government or any agency thereof. 


\section{DISCLAIMER}

Portions of this document may be illegible in electronic image products. Images are produced from the best available original document. 
HIGH PRESSURE CALIBRATION WITH A NEW ABSOLUTIF PRESSURE GAUGE

by

Arthur L. Ruoff, R. C. Lincoln, , and Y. C. Chen

Department of Materials Science and Engineering Cornell University, I thaca, New York

Abstract

Based on the simultaneous measurement of length and transit time of a specimen under pressure, we have developed a new way of determining absolute high pressure. The mercury freezing point at $0{ }^{\circ} \mathrm{C}$ has been determined with this new method at $7571.2 \pm 1.6$ bars. Accurate high pressure calibration of secondary pressure gauge such as manganin gauge is possible with this method. The maximum deviation from linearity of the present gauge studied is $11.6 \pm .1$ bars between atmospheric pressure and the mercury freezing point at $0^{\circ} \mathrm{C}$.

$\therefore$ present address: Sandia Corporation, Albuquerque, New Mexico 
If the linear compressibility of a material is isotropic, it is easy to show that the pressure can be expressed in the form

$$
\mathrm{P}=\mathrm{P}_{1}-3 \rho_{1} l_{1}^{3} \int_{l_{1}}^{\ell}\left(\frac{1}{\tau l^{2}}-\frac{4}{3_{\tau}^{2}}\right)\left(\frac{1}{1+\Delta(\mathrm{P})}\right) \frac{\mathrm{d} \ell}{\ell^{2}}
$$

where

$$
\Delta(\mathrm{P})=\frac{\beta^{2} \mathrm{~B}^{\mathrm{T}} \mathrm{T}}{\rho \mathrm{C} \mathrm{p}}
$$

Here $\rho_{1}$ and $\ell_{1}$ are the density and length at atmospheric pressure $\mathrm{P}_{1}, \tau_{\ell}$ and $\tau_{\mathrm{s}}$ are transit times for [111] longitudinal wave and [100] shear wave respectively, $\beta$ is the volume thermal expansion coefficient, $B^{S}$ is the adiabatic bulk modulus, $T$ is the absolute temperature and $C_{p}$ is the specific heat of the material. It is obvious then from equation (1), the pressure can be determined if length $\ell$ and transit times $\tau_{l}$ and $\tau_{s}$ are measured at the same temperature and pressure.

We choose silicon as our specimen for the following two reasons: ( 1 ) because $\Delta(P)$ is quite small $(\Delta(P) \leq 0.0011$ for $0 \leq \mathrm{P} \leq \mathrm{P} H \mathrm{H}$, $\mathrm{p}_{\mathrm{Hg}}$ is the freezing pressure of mercury at $0^{\circ} \mathrm{C}$ ) and moreover can be accurately evaluated, (2) because excellent single crystals of silicon can be grown and hence the material can be expected to behave reversibly.

The fractional length change measurement is accurate to $4 \times 10^{-8}$ and utilizes a meter long specimen; it is described elsewhere. $(1,2)$ Briefly; end positions of specimen are defined by special H-shaped soft magnetic cores which are located with two linear variable differential transformers (LVDT) external to the pressure vessel by a null technique. The length change is measured by a Fabry Perot 
interferometer with laser beams traveling in a vacuum bellows, between mirrors aligned.with centers of LVDT on carriages.: The entire system along with ultrasonic pressure vessel are immersed in a constant temperature both controlled to $2 \times 10^{-3} \mathrm{C}$. The initial length $\ell_{1}$ at atmospheric pressure is measured interferometrically against a standard length. The fractional error of the original length of the specimen $\ell_{1}$ is $1 \times 10^{-5}$.

The silicon specimens used for ultrasonic measurements were made from single crystals of the same purity as that used in the length measurement. The transit times were measured with pulse superposition technique. The reproducibility of transit time measurement was within $2 \times 10^{-5}$.

After data for length measurement and ultrasonic transit time were collected, analysis was done by nonlinear least square analysis for fitting Murnaghan equation and Simpson's rule was utilized for integration to obtain P vs $l$ data. Meanwhile, we obtained simultaneously the calibrations for manganin gauge.

The mercury freezing point at $0^{\circ} \mathrm{C}, \mathrm{P}_{\mathrm{Hg}}$, was then determined using a pressure arrest method (zero rate change of pressure versus time:at transition point). It was determined to be $7571.2 \pm$. 1.6. bars...

The quadratic dependence of pressure on the ratio of change of manganin resistance and initial resistance $\left(\frac{\Delta R}{R_{1}}\right)$ was fitted. The maximum deviation of the gauge from linearity about midway between $P_{1}$ and $P_{H g}$ was determined to be: $\Delta P_{M}=11.6 \pm .1$ bars:

Tabic 1 tabulates the value of $\Delta \mathrm{P}_{\mathrm{M}}$ observed by different workers. Direct comparison of $\Delta \mathrm{P}_{M}$ may not be meaningful since it 
is conceivable that $\Delta \mathrm{P}_{\mathrm{M}}$ varies with the manganin sample. It is, however, also conceivable that $\Delta \mathrm{P}_{\mathrm{M}}$ is not very strongly dependent on the sample (assuming its purity and fabrication are nearly the same) as Bridgman proposed but rather dependent on the inaccurate measurement of pressure. At this point. we do not believe the answer is known. To compare the relative reliability of the nonlinearity or $\Delta \mathrm{P}_{\mathrm{M}}$ measured by our pressure gauge and that measured by the free piston gauge, let us assume a random error of 2 bars at each pressure for the free piston gauge. Thus the value of $\Delta P_{M}$ would be known to at best \pm 1 bar. The random error of an individual reading in the present system is 0.04 bars or 1ess. Consequently, $\Delta \mathrm{P}_{\mathrm{M}}$ can easily be measured to 0.0 .5 bars. It is important to know $\Delta \mathrm{P}_{\mathrm{M}}$ accurately in many applications. For example, if the pressure derivative of the bulk modulus of iron is measured by length change, an error of 2 bars in $\Delta \mathrm{P}_{\mathrm{M}}$ would give an error of near 1 y $10 \%$ in $B_{0}^{\prime}{ }^{1}$

Values of the $0^{\circ} \mathrm{C}$ mercury freezing pressure are given in Table 2. It should be noted that the Committee on Fixed Points Near Room Temperature at the Symposium on Accurate Characterization of the High - Pressure Environment held at the National Bureau of Standards, Gaithersburg, Md. in 1968 designated $7569 \pm 2$ bars as the accepted value for the $0^{\circ} \mathrm{C}$ mercury freezing pressure. $(3,4)$

\section{Acknowledgement}

We would like to thank Robert E. Terry for his technical. assistance. We acknowledge the support of this work by the United States Atomic Energy Commission: 
Table 1. Values of $\Delta \mathrm{P}_{\mathrm{M}}$

\begin{tabular}{cc}
$\frac{\Delta \mathrm{P}_{\mathrm{M}} \text { (bars) }}{-10}$ & Harwood $^{5}$ \\
-11 & NBS $^{6}$ \\
-21 & Zeto and Vanfleet \\
-21 & Boren, Babb and Scott \\
$-11.6 \pm .1$ & Present Work \\
\hline
\end{tabular}

Table 2. The $0^{\circ} \mathrm{C}$ Mercury Freezing Pressure

\begin{tabular}{cc} 
Pressure (bars) & Source \\
$7565.4 \pm 3.7$ & Newhal1, Abbot and Dunn \\
$7569.2 \pm 1.2$ & Dadson and Greig ${ }^{10}$ \\
$7571.0 \pm 1.2$ & Yasunami \\
$7571.2 \pm 1.6$ & Present \\
\hline
\end{tabular}




\section{References}

1. R. C. Lincoln, Ph.D Thesis, Cornell University, Ithaca, New York. (1971).

2. R. C. Lincoln and A. L. Ruoff, Rev. Sci. Instr. (to be submitted for publication).

3. Nat. Bur. Sta., Spec. Pub. 326 (1971):p. 313.

4. E. C. Lloyd and C. W. Beckett, Science 164,860 (1969).

5. D. H. Newha11, Harwood Engineering, Pirvate Communication.

6. D. P. Johnson, National Bureau of Standards, Private Communication with R. C. Lincoln.

7. R. J. Zeto and H. B. Vanfleet, J. Appl. Phys. 40, 2227. (1969).

8. M. D. Boren, S. E. Babb, Jr., and G. J. Scott, Rev. Sci. Instr. 36, 1456 (1965).

9. D. H. Newha11, L.H. Abbot and. R. A. Dunn, in High Pressure Measurement, ed. by A. A. Giardini and E. C. Lloyd, Butterworths, Washington (1963) p. 339.

10. R. S. Dadson and R. G. P. Greig, Brit. J. Appl. Phys. 16, 1711 (1965).

11. K. Yasunami, Proc. Jap. Acad. 43, 310 (1967). 